\title{
USE OF PROTON PUMP INHIBITORS AND RISK OF ISCHEMIC EVENTS IN THE GENERAL POPULATION
}

\section{AUTHORS}

Manuela Casula ${ }^{a}$, Lorenza Scotti ${ }^{b}$, Federica Galimberti ${ }^{a}$, Francesco Mozzanicaa ${ }^{a}$ Elena Tragni ${ }^{a}$, Giovanni Corrao ${ }^{b}$, Alberico L Catapano ${ }^{a, c}$

\section{Affiliation}

${ }^{a}$ Epidemiology and Preventive Pharmacology Centre (SEFAP), Department of Pharmacological and Biomolecular Sciences, University of Milan, via Balzaretti 9, 20133 Milan, Italy

${ }^{\mathrm{b}}$ Department of Statistics and Quantitative Methods, Division of Biostatistics, Epidemiology and Public Health, University of Milano-Bicocca, Via Bicocca degli Arcimboldi 8, 20126 Milan, Italy 'IRCCS MultiMedica, via Milanese 300, 20099 Sesto S. Giovanni (MI), Italy

\section{CORRESPONDENCE}

Manuela Casula

Epidemiology and Preventive Pharmacology Centre (SEFAP), Department of Pharmacological and Biomolecular Sciences, University of Milan, via Balzaretti 9, 20133 Milan, Italy

Tel +3902503 18428. Fax +390250318386

E-mail: manuela.casula@unimi.it

Number of figures and/or tables: 5 


\section{ABSTRACT}

BACKGROUND AND AIM A potential increased risk of cardiovascular events has been suggested for proton pump inhibitors (PPIs), the most commonly prescribed drugs for the management of upper gastrointestinal disorders. We aimed to estimate the risk of hospitalization for cardio/cerebrovascular (CV) events in a cohort of incident PPI users.

METHODS A nested case-control study was carried out using regional healthcare utilization databases. For each case (hospitalization for non-haemorrhagic CV event), up-to-five controls randomly selected from the cohort were matched by gender, age at cohort entry, and index date. Exposure was estimated as recency of therapy (current, recent and past users) and number of days covered. Adjusted conditional logistic regression was used to estimate the association between exposure and outcome.

RESULTS Among new PPI users, we identified 17,832 cases and 89,160 controls (males 64.9\%; mean age 58.9 years). Cases showed a significantly higher prevalence of use of drugs for diabetes, hypertension and hypercholesterolemia than controls. Risk of CV events was significantly higher for current (OR $1.61 ; 95 \% \mathrm{Cl} 1.55-1.68)$ and recent users (OR $1.15 ; 95 \% \mathrm{Cl} 1.06-1.26)$ compared to past users. Analogous results were found stratifying for cardiovascular (OR current $_{1.71 ; 95 \% \mathrm{Cl} 1.63-1.81)}$ and cerebrovascular events $\left(\mathrm{OR}_{\text {current }} 1.43 ; 95 \% \mathrm{Cl} 1.34-1.54\right)$. The increased risk was confirmed in subgroups by antithrombotic, statin use, or exposure duration. The same analysis for $\mathrm{H} 2$-antagonists use showed no significant results.

CONCLUSIONS In primary care setting, PPI use was independently associated with increased risk of first-time cardiovascular event, consistent with the evidence that PPIs adversely impact vascular function, underlying the need to promote appropriate prescribing of these drugs.

Keywords: Proton pump inhibitors, cardio/cerebrovascular events, case-control study, databases 


\section{INTRODUCTION}

Proton pump inhibitors (PPIs) are among the most commonly prescribed drugs for the management of upper gastrointestinal disorders, such as gastroesophageal reflux disease (GERD), peptic or duodenal ulcer disease and dyspepsia $(1,2)$. Increasing of GERD prevalence in Western countries and Asia during the last 20 years as well as the undoubted effectiveness of these drugs are extensively demonstrated by previous studies $(3,4)$. Furthermore, the beneficial effects even after short-term therapy with an improvement of patient's quality of life, together with the belief that PPIs are essentially safe, lead to a widespread prescription of these drugs (5). Indeed, several publications have shown the inappropriate use of these drugs during hospitalization as well as in primary care $(6,7)$. Within this scenario, a potential increased risk of serious adverse drug reactions as cardiovascular and cerebrovascular events has been reported and is a matter of concern (8-10). The increased cardiovascular morbidity in patients exposed to PPIs was firstly related to a potential interaction with clopidogrel $(11,12)$. As a consequence, based on the results of two long-term randomized controlled trials (RCTs) showing that severe cardiovascular events were more common in patients with GERD being treated with omeprazole or esomeprazole compared to subjects undergoing to surgery $(13,14)$, in 2009 the Food and Drug Administration (FDA) issued a safety warning recommending to avoid the co-administration because it could result in significant reductions in clopidogrel's active metabolite levels and antiplatelet activity. Even if concerns remain on the epidemiology of this interaction and the intensity of the clinical effect, several more recent studies have found that PPIs may independently affect vascular function (15-18) and a recent metaanalysis of 16 RCTs showed a significant $70 \%$ increased risk of cardiovascular events among patients treated with PPIs as monotherapy (17).

The correct evaluation and quantification of an increase in cardiovascular risk associated with the use of PPIs is essential in the context of widespread and sometimes unnecessary use of these drugs. Therefore, we conducted a nested case-control study aimed to estimate the risk of hospitalization for cardiovascular and cerebrovascular events associated with PPI exposure.

\section{METHODS}

\section{Data source}


In Italy, the National Health Service (NHS) provides universal, free-of-charge coverage to all inhabitants for many healthcare services. For the present study, data were retrieved from the healthcare utilization databases of the Italian Lombardy region. The regional automated system of databases collects a variety of information (19), including:

(1) an archive of residents who receive NHS assistance, reporting demographic and administrative data;

(2) a database of the outpatient drug prescriptions reimbursable by the NHS;

(3) a database on diagnosis at discharge from public or private hospitals of the region.

For each patient, we linked the aforementioned databases via a single identification code. In order to preserve privacy, each identification code was automatically converted into an anonymous code; the inverse process was prevented by deletion of the conversion table.

\section{Cohort selection and follow-up}

The target population consists of all beneficiaries of the NHS, resident in Lombardy with age >=18 and $<=70$ years. A cohort of incident PPI users was identified. Exposure to PPI was inferred from the presence of prescriptions for any drug belonging to the class in the prescription database. Since in Italy the availability of these drugs as OTC started at the end of 2010, this approach guarantees the correct identification of exposed patients during the study period. Subjects with at least one prescription of PPIs (ATC A02BC) from January 1, 2003 until December 31, 2007 were identified, and the date of first prescription was defined as the index date.

Patients were excluded from data analysis if: i) they had received any PPIs within the 3 years before the index date to ensure the selection of only incident users of PPIs; ii) they had received any histamine-2 receptor $(\mathrm{H} 2)$ antagonists drugs within the 3 years before the index date and/or during follow-up to explore the effect of PPIs excluding the potential effect of other drugs with similar indication; iii) they were hospitalized for any cardiovascular or cerebrovascular events or they were treated with any anticoagulant or antiplatelet therapy (regardless if primary or secondary prevention) in the 3 years before the index date to avoid the inclusion of patients with previous cardiovascular problems; iv) they were hospitalized for tumours or cancer treatments in the 3 years before the index date; v) they had less than 57 days of follow-up from index date to ensure that all subjects have the same probability of falling in any of the exposure category. Each member of the cohort accumulated person-years of follow-up from the index date until the earliest event among: 
hospitalization for any cardiovascular or cerebrovascular events (see below), death, emigration, or end of follow-up (December 31, 2010).

\section{Selection of cases and controls}

A nested case-control study was performed into the cohort of incident PPIs users. Cases were members of the cohort who during follow-up were hospitalized for ischemic heart disease (ICD-9 code 410-414, 425, 427, 428) and/or cerebrovascular disease excluding haemorrhagic events (ICD9 code 433-435). The earliest date of hospital admission was considered as the event date.

For each case patient, up to five controls randomly selected from the cohort were matched by gender, age at cohort entry, and index date. In this way, every set constituted by the index case and the corresponding controls had the same period of observation.

\section{Assessing exposure to PPIs}

Exposure was evaluated as:

- recency, which quantifies the time from the last day of prescription during follow-up and the event date. Specifically, we defined:

- current users, having the last day covered by PPI therapy within 28 days before event date;

- recent users, having the last day covered by PPI therapy between 29 and 56 days before event date;

- $\quad$ past users, having the last day covered by PPI therapy more than 56 days before event date;

- days covered by therapy, calculated as the cumulative number of days of therapy, based on the defined daily dose (DDD), estimated in the last continuous coverage period (cut-off at 28 daily doses of exposure to PPIs).

\section{Covariates}

The information on several confounding variables were also retrieved. As data on diagnosis are not included in the administrative databases, we considered the use of antidiabetic (ATC A10B), antihypertensive $(\mathrm{CO2}, \mathrm{C03}, \mathrm{C07}, \mathrm{C08}, \mathrm{C09})$ and lipid-lowering drugs (C10A) as a proxy for the presence of diabetes, hypertension and hypercholesterolemia, respectively. The use of these drugs, 
NSAID (Non-Steroidal Anti-Inflammatory Drug) use except coxibs (M01AA, M01AB, M01AC, M01AE, M01AG, M01AX), coxib use (M01AH), corticosteroid use (H02AB, H02BX01) and the Charlson comorbidity index (20) were evaluated both in the 3 years before index date and during follow-up, while the antithrombotic use (ATC B01A) was assessed only during follow-up.

\section{Data analysis}

Chi-square and t tests were used to evaluate the differences between cases and controls of categorical and continuous variables respectively. Conditional logistic regression models were fitted to estimate the adjusted odds ratio (aOR) and the corresponding 95\% confidence interval $(\mathrm{Cl})$, of cardiovascular (CV) events in relation to exposure to PPIs. Adjustments were made for type of PPI and the above reported covariates. The analyses were performed considering as outcome the hospitalization for any cardiovascular disease and separately cardiovascular and cerebrovascular events. Trends in aORs were tested, when feasible, according to the statistical significance of the regression coefficient of the recorded variables obtained by scoring the corresponding categories. Moreover, a stratified analysis was performed considering the following variables: use of antithrombotics, statins, antidiabetic and antihypertensive drugs used during follow-up, age ( $\leq 60 \mathrm{vs}$ $>60$ years) and gender to assess if the effect of the current use of PPIs on the onset of CV disease varied among strata. The differences between strata were tested including in the model an interaction term between exposure and stratification variables.

All analyses were performed using the Statistical Analysis System Software (version 9.4; SAS Institute, Cary, NC, USA). Statistical significance was set at the 0.05 level. All p-values were twosided.

\section{Sensitivity analyses}

To verify the robustness of our findings, we performed the following sensitivity analyses.

The same analysis described above was repeated modifying the definition of recency: first, with different windows of exposure (current users $\leq 14$ days, recent users 15-28 days; past users >28 days); second, considering the prescription date instead of the last day covered (current users as having last prescription of PPIs within 28 days before event date; recent users as having the last prescription of PPIs between 29 and 56 days before event date; past users as having the last prescription of PPIs over than 56 days before event date). 
Furthermore, to test a possible indication bias, we conducted a parallel case-control study nested in a cohort of incident users of $\mathrm{H} 2$ antagonists, a different class of drugs with the same therapeutic indications as PPIs, excluding patients who had received any PPIs within the 3 years before the index date and/or during follow-up. The definitions for exposure and events were the same used in the main PPI analysis.

\section{RESULTS}

According to our inclusion and exclusion criteria (Supplemental Figure 1), we enrolled 737,369 subjects aged 18-70, free from cardiovascular disease at cohort entry, non-users of antithrombotic drugs or $\mathrm{H} 2$ antagonists, and with at least 57 days of follow-up, who were incident users of PPIs in the period 2003-2007. Within this cohort, we identified 17,832 case patients with a hospitalization for ischemic heart disease ( $N$ 11,616) and/or non-hemorrhagic cerebrovascular disease ( $N$ 6467) and matched them with 89,160 controls.

As shown in Table 1, mean age (SD) of cases and controls was 58.89 years (9.05 years) and 64.9\% of them were men (matching variables). Esomeprazole, omeprazole, and lansoprazole were the PPI agents more commonly prescribed. As compared to controls, use of drugs for diabetes, hypertension, or hypercholesterolemia was more common among cases, as well as the comorbidity (by Charlson score) was higher, while use of non-selective NSAIDs or coxibs was not different between cases and controls. Distribution by recency classes was quite different: current users represented $24.6 \%$ of cases and $14.4 \%$ of controls.

Table 1. Characteristics of the case patients and of the corresponding controls included into the study

In the multivariable-adjusted regression analysis, risk of CV events was significantly higher for current (aOR 1.61, 95\% $\mathrm{Cl} 1.55-1.68)$ and recent users (aOR 1.15, 95\% $\mathrm{Cl} 1.06-1.26)$ compared to past users (Table 2). There was no statistical evidence that the effect of PPIs on cardiovascular risk differed according to type of PPI, as prescribed at starting therapy. 
Table 2. Association between PPI use and risk of hospitalization for cardiovascular or non-haemorrhagic cerebrovascular events

Results were confirmed by the stratified analysis for cardiovascular (current: aOR 1.71, 95\% $\mathrm{Cl}$ 1.631.81) and cerebrovascular events (current: aOR 1.43, 95\% $\mathrm{Cl} 1.34-1.54)$ (Table 3).

Table 3. Association between PPI use and risk of hospitalization for cardiovascular and non-haemorrhagic cerebrovascular events

The increased risk was not influenced by exposure duration: compared to past users, the aOR for current users with $\leq 28$ daily doses (67.2\% of current cases and $69.2 \%$ of current controls) was 1.61 (95\% $\mathrm{Cl} 1.53-1.69)$ and for current users with $>28$ daily doses was 1.62 (95\% $\mathrm{Cl} 1.51-1.73)$. In the comparison between current users $\leq 28$ daily doses vs current users $>28$ daily doses, OR was 0.99 (95\%Cl 0.92-1.07).

The stratified analysis (Figure 1) showed a significant difference among strata of antithrombotic use during follow-up ( $p$-value 0.002 ) and age ( $p$-value $<0.0001)$. In particular, antithrombotic users had an higher risk of CV events compared to non-users (aOR 1.74 vs 1.52) as well as younger subjects compared to older ones (aOR 1.78 vs 1.50 ).

Figure 1. Association between current use of PPIs (vs past use) and risk of hospitalization for cardiovascular or non-haemorrhagic cerebrovascular events by age, gender, or concomitant use of drugs

The results were also confirmed by the sensitivity analysis, which tested different definitions of PPI use recency (Supplemental Table 1).

Finally, we evaluated whether the increased risk of cardiovascular and cerebrovascular events observed with current vs past PPI use was also present among current users vs past users of $\mathrm{H} 2$ antagonists. In this nested case-control study, we identified 427 case patients, matched with 2,133 controls; mean age (SD) of cases and controls was 58 years ( 9.7 years) and $68.6 \%$ of them were men. 
Distribution by recency classes was similar ( $p$-value 0.8179 ) between cases and controls (current users represented $4.5 \%$ of cases and $3.5 \%$ of controls). The multivariable-adjusted regression analysis on the effect of $\mathrm{H} 2$ antagonists use showed no significant results (Table 4).

Table 4. Risk of hospitalization for cardiovascular or non-haemorrhagic cerebrovascular events by recency of $\mathrm{H} 2$ antagonist use

\section{DISCUSSION}

Proton pump inhibitors are the most effective gastric acid-suppressing agents and have revolutionized the treatment of upper gastrointestinal tract disorders and the prevention of gastric complications associated with the use of non-steroidal anti-inflammatory drugs (21). Their effectiveness and their favourable tolerance profile have made them one of the most used drug classes. However, PPIs are used too often or too long in patients with insufficient indications $(8,9)$. Concern about their over-utilization has led to investigate potential adverse effects, and recent literature has suggested a number of safety issues associated with the use of PPIs $(10,22,23)$, including increase of cardiovascular risk.

Early evidence of increased cardiovascular risk associated with pump-inhibitor therapy dates back a decade ago $(24,25)$, when it was suggested that omeprazole administration in clopidogrel-treated patients could inhibit CYP2C19, responsible for the activation of the prodrug clopidogrel, with consequent reduction in antiplatelet activity and increased CV risk. Along with these data, evidence has been collected over time in favor of possible PPI effects on cardiovascular outcome regardless of antiplatelet therapy. To evaluate whether PPI use associates with first-time myocardial infarction in the general population, Shih et al. (16) designed a propensity score-matched study and a casecrossover study. They found a hazard ratio of $1.58(95 \% \mathrm{Cl} 1.11-2.25)$ in the analysis of PPI use periods matched to PPI non-use periods, and an aOR of $4.61(95 \% \mathrm{Cl} 1.76-12.07)$ in the casecrossover analysis (1-7 days before the index date vs 8-14 days before the index date). The same analysis was conducted using $\mathrm{H} 2$ antagonists as negative control and NSAIDs as positive controls, yielding in a non-significant result and in an aOR of 1.55 (95\% Cl 1.27-1.89), respectively. Similarly, Wang et al. (18) studied the association with first-time ischemic stroke using a propensity score- 
matched study and a nested case-control study. They found a hazard ratio of $1.36(95 \% \mathrm{Cl} 1.14-1.62)$ in the analysis of PPI use periods matched to PPI non-use periods, which remained significant comparing to $\mathrm{H} 2$ antagonist use ( $\mathrm{HR} 1.49 ; 95 \% \mathrm{Cl} 1.10-2.02)$. In the nested case-control analysis on more than 30.000 subjects, they found aORs of 1.77 (95\% $\mathrm{Cl} 1.45-2.17)$ within 30 days before the hospitalization of first-time ischemic stroke, $1.65(95 \% \mathrm{Cl} 1.31-2.08)$ between 31 and 90 days, and $1.28(95 \% \mathrm{Cl} 1.03-1.59)$ between 91 and 180 days before the event, as compared with those without stroke, while the proportions of $\mathrm{H} 2$ antagonist users and non-users were comparable. Of note, these studies were conducted using data from the National Health Insurance Research Database of Taiwan and, according to the Taiwan Bureau of NHI, reimbursement guidance on PPI prescriptions is limited to patients with peptic ulcer disease with or without complications or gastroesophageal reflux disease, with a treatment duration mostly limited to 4 months. Shah et al. (26) investigated the association between PPIs and MI using an innovative data mining approach and showing that PPIs as a class were associated with $\mathrm{MI}$ with an aOR of $1.16(95 \% \mathrm{Cl} 1.09-1.24)$; the associations persist after excluding patients on clopidogrel (aOR 1.14; 95\% Cl 1.06-1.24), while no association was showed for $\mathrm{H} 2$ antagonists $(\mathrm{aOR} 0.93 ; 95 \% \mathrm{Cl} 0.86-1.02)$. Moreover, in a prospective cohort of patients undergoing elective coronary angiography, survival analysis revealed an increased cardiovascular mortality among PPI users during about 5 years of follow-up (HR $2.00,95 \% \mathrm{Cl} 1.07-$ 3.78). Recently, in a study of Danish individuals without prior atherosclerotic disease, PPI use was associated with a significantly increased risk of ischemic stroke (HR 1.13; 95\% $\mathrm{Cl} 1.08-1.19)$ and $\mathrm{MI}$ ( $\mathrm{HR} 1.31 ; 95 \% \mathrm{Cl}$ 1.23-1.39), with a dose-response relationship, and no significant association between use of $\mathrm{H} 2$ antagonists (27). In our study, a nested case-control study in a cohort of incident PPI users, we found a significantly increased risk of hospitalization for CV events for current (aOR $1.61 ; 95 \% \mathrm{Cl} 1.55-1.68)$ and recent users (aOR 1.15; $95 \% \mathrm{Cl} 1.06-1.26)$ compared to past users, regardless of the type of PPI. Results were consistent in stratified analyses, by type of outcome (cardiovascular or cerebrovascular events), by antithrombotic use, and by exposure duration.

A major limitation of an observational study is that statistical analyses can only identify associations between independent variables and the outcome of interest, and this limit of our findings is shared with the other studies mentioned above, since much of the evidence supporting the association between PPI exposure and increased cardiovascular risk stems from pharmacoepidemiological studies (28-30). Causal conclusions from observational studies typically require to support plausibility through biologic evidence and to exclude confounding. 
Several possible biologic mechanisms to explain the association have been proposed in literature. The most credited hypothesis derived from the observation that an impairment of NOS (Nitric Oxide Synthase) pathway resulting in a promotion of ischemic conditions $(16,31,32)$. In fact, all PPI class members can directly inhibit dimethylarginine dimethylaminohydrolase (DDAH) (31) activity. The consequence is an elevation of asymmetric dimethylarginine (ADMA), a circulating inhibitor of NOS, justifying the increase in cardiovascular risk, since accumulating evidence from epidemiological studies indicates that humans with impaired NOS activity are at greater risk of CV events $(33,34)$. Of note, the studies investigating the association between PPIs and CV risk have paid particular attention to the use of strategies, both in the design and in the analysis, that minimized these biases (35), such as the adjustment for cardiovascular therapies, use of the propensity score, the new-users design (36), the use of $\mathrm{H} 2$ antagonists as negative controls (37). A potential source of confounding may be an increased use of acid-suppressing drugs in the period before hospitalization, because prodromal symptoms of MI could be misinterpreted as dyspepsia (38). Supporting this hypothesis, in a case-crossover study showing that PPI prescription enhanced the risk of $\mathrm{MI}$ by $70 \%$, this increase was mitigated when the dispensation date was considered instead of the prescription date (39). A potential factor that must be considered is the confounding by indication, i.e. the possibility that the increase in risk is determined by the pathology treated with PPIs, rather than by the drugs themselves (40). Indeed, a population-based study reported a risk for cardiovascular adverse events with PPI therapy, but it also revealed a risk of similar magnitude with other drugs without known cardiac toxicity (41). To account for confounding by indication, in the current study was applied the so-called "user-only design" by restricting the target population only to patients who used the drug of interest making exposed (current users) and non-exposed (past users) groups comparable for baseline outcome risk. Notably, in our study subjects treated with PPIs were included regardless of indication. Furthermore, the analysis on the effect of $\mathrm{H} 2$ antagonist utilization, used as negative control since they are prescribed with the same indications, showed no significant results. The same approach was adopted by other observational studies that have not shown an increase in risk as well $(15,18,26,42)$.

Another limitation of our study, inherent to the use of administrative databases as sources of data, is the impossibility to account for factors related to the pathophysiological status and lifestyle of the patient, with the exception of what can be deduced from the use of prescribed drugs. For example, we could not take into account the use of low-dose aspirin (which is associated both with a higher $\mathrm{CV}$ risk and with a higher risk of upper GI bleeding, and therefore of the use of PPIs). This because 
low-dose aspirin is available both as a reimbursed drug for cardiovascular prevention (therefore traceable in administrative databases) and as OTC formulation with analgesic/anti-inflammatory indication, and its low cost makes it a largely practiced option. This prevents us from providing reliable prevalence estimates of use of low-dose aspirin and using the data as adjustment variable. Similarly, information on the use of NSAIDs and coxibs was collected; these covariates were intended to be a proxy of the pathological state of the patient, to be included as adjustment variables in the multivariate model. With regard to these variables, the modest risk reduction shown in our analysis, although evaluated on a cohort of PPI users and without quantifying the exposure, may deserve further study.

As implemented by applying methods based on the propensity score $(18,42)$, taking these factors into account could help to control for some confounding factors. Nevertheless, it should be remembered that PPI users tend to be sicker than PPI nonusers, and it is difficult to adjust these baseline differences. For this reason, this cause-and-effect relationship between PPI use and CV events still should be tested in further detail by a randomized prospective trial.

In conclusion, consistent with the evidence that PPIs may adversely impact vascular function, in this study PPI use was independently associated with an increased risk of first-time cardiovascular event in the general population. This association certainly deserves further investigation; however, these results, along with the most recent evidence suggesting a less favourable safety profile, highlight the urgency of critically reviewing the use of PPIs, at least in those situations where their use is not recommended.

\section{Conflict of Interest statement}

All authors have completed the Conflict of Interest Disclosure form and declare: no support from any organisation for the submitted work; no financial relationships with any organisations that might have an interest in the submitted work in the previous three years; no other relationships or activities that could appear to have influenced the submitted work.

\section{Financial support}

No Funding/Support 
No financial disclosures

\section{Author contributions}

MC, FM, LS, and FG were responsible for the study concept and design. LS and FG did the analysis. GC, ET, and ALC contributed to the data analysis and interpretation of the results. MC and FG drafted the manuscript and all authors critically revised for important intellectual content and approved the final manuscript.

\section{Ethics statement}

According to the rules from the Italian Medicines Agency, retrospective studies without direct contact with patients do not need a written consent to process personal data when they are used for research aims.

\section{BIBLIOGRAPHY}

1. Barozzi N, Tett SE. Gastroprotective drugs in Australia: utilization patterns between 1997 and 2006 in relation to NSAID prescribing. Clin Ther. 2009 Apr;31(4):849-61. PubMed PMID: 19446158. Epub 2009/05/19. eng.

2. Rotman SR, Bishop TF. Proton pump inhibitor use in the U.S. ambulatory setting, 2002-2009. PloS one. 2013;8(2):e56060. PubMed PMID: 23418510. Pubmed Central PMCID: 3572154.

3. Edwards SJ, Lind T, Lundell L. Systematic review of proton pump inhibitors for the acute treatment of reflux oesophagitis. Alimentary pharmacology \& therapeutics. 2001 Nov;15(11):1729-36. PubMed PMID: 11683686.

4. Sachs G, Shin JM, Howden CW. Review article: the clinical pharmacology of proton pump inhibitors. Alimentary pharmacology \& therapeutics. 2006 Jun;23 Suppl 2:2-8. PubMed PMID: 16700898.

5. Eid SM, Boueiz A, Paranji S, Mativo C, Landis R, Abougergi MS. Patterns and predictors of proton pump inhibitor overuse among academic and non-academic hospitalists. Intern Med.49(23):2561-8. PubMed PMID: 21139293. Epub 2010/12/09. eng.

6. George CJ, Korc B, Ross JS. Appropriate proton pump inhibitor use among older adults: a retrospective chart review. Am J Geriatr Pharmacother. 2008 Dec;6(5):249-54. PubMed PMID: 19161927. Epub 2009/01/24. eng.

7. Lodato F, Poluzzi E, Raschi E, Piccinni C, Koci A, Olivelli V, et al. Appropriateness of Proton Pump Inhibitor (PPI) prescription in patients admitted to hospital: Attitudes of general practitioners and hospital physicians in Italy. European journal of internal medicine. 2016 May;30:31-6. PubMed PMID: 26926561.

8. Freedberg DE, Kim LS, Yang YX. The Risks and Benefits of Long-term Use of Proton Pump Inhibitors: Expert Review and Best Practice Advice From the American Gastroenterological Association. Gastroenterology. 2017 Mar;152(4):706-15. PubMed PMID: 28257716.

9. Nealis TB, Howden CW. Is there a dark side to long-term proton pump inhibitor therapy? Am J Ther. 2008 Nov-Dec;15(6):536-42. PubMed PMID: 19127138. Epub 2009/01/08. eng. 
10. Schnoll-Sussman F, Katz PO. Clinical Implications of Emerging Data on the Safety of Proton Pump Inhibitors. Current treatment options in gastroenterology. 2017 Mar;15(1):1-9. PubMed PMID: 28130652. Epub 2017/01/29. eng.

11. Juurlink DN. Proton pump inhibitors and clopidogrel: putting the interaction in perspective. Circulation. 2009 Dec 8;120(23):2310-2. PubMed PMID: 19933929.

12. Juurlink DN, Gomes T, Ko DT, Szmitko PE, Austin PC, Tu JV, et al. A population-based study of the drug interaction between proton pump inhibitors and clopidogrel. CMAJ. 2009 Mar 31;180(7):713-8. PubMed PMID: 19176635. Pubmed Central PMCID: 2659819.

13. Lundell L, Attwood S, Ell C, Fiocca R, Galmiche JP, Hatlebakk J, et al. Comparing laparoscopic antireflux surgery with esomeprazole in the management of patients with chronic gastro-oesophageal reflux disease: a 3-year interim analysis of the LOTUS trial. Gut. 2008 Sep;57(9):1207-13. PubMed PMID: 18469091. Pubmed Central PMCID: 2565581.

14. Lundell L, Miettinen P, Myrvold HE, Hatlebakk JG, Wallin L, Engstrom C, et al. Comparison of outcomes twelve years after antireflux surgery or omeprazole maintenance therapy for reflux esophagitis. Clinical gastroenterology and hepatology : the official clinical practice journal of the American Gastroenterological Association. 2009 Dec;7(12):1292-8; quiz 60. PubMed PMID: 19490952.

15. Charlot $\mathrm{M}$, Ahlehoff $\mathrm{O}$, Norgaard ML, Jorgensen $\mathrm{CH}$, Sorensen $\mathrm{R}$, Abildstrom SZ, et al. Proton-pump inhibitors are associated with increased cardiovascular risk independent of clopidogrel use: a nationwide cohort study. Annals of internal medicine. 2010 Sep 21;153(6):378-86. PubMed PMID: 20855802.

16. Shih CJ, Chen YT, Ou SM, Li SY, Chen TJ, Wang SJ. Proton pump inhibitor use represents an independent risk factor for myocardial infarction. International journal of cardiology. 2014 Nov 15;177(1):292-7. PubMed PMID: 25499395.

17. Sun S, Cui Z, Zhou M, Li R, Li H, Zhang S, et al. Proton pump inhibitor monotherapy and the risk of cardiovascular events in patients with gastro-esophageal reflux disease: a meta-analysis. Neurogastroenterology and motility : the official journal of the European Gastrointestinal Motility Society. 2017 Feb;29(2). PubMed PMID: 27577963. Epub 2016/09/01. eng.

18. Wang YF, Chen YT, Luo JC, Chen TJ, Wu JC, Wang SJ. Proton-Pump Inhibitor Use and the Risk of FirstTime Ischemic Stroke in the General Population: A Nationwide Population-Based Study. Am J Gastroenterol. 2017 Jul;112(7):1084-93. PubMed PMID: 28397874. Epub 2017/04/12. eng.

19. Corrao G, Cesana G, Merlino L. Pharmacoepidemiological research and the linking of electronic healthcare databases available in the Italian region of Lombardy. BioMed Stat Clin Epidemiol. 2008;2(2):11725.

20. Charlson ME, Pompei P, Ales KL, MacKenzie CR. A new method of classifying prognostic comorbidity in longitudinal studies: development and validation. Journal of chronic diseases. 1987;40(5):373-83. PubMed PMID: 3558716.

21. Strand DS, Kim D, Peura DA. 25 Years of Proton Pump Inhibitors: A Comprehensive Review. Gut and liver. 2017 Jan 15;11(1):27-37. PubMed PMID: 27840364. Pubmed Central PMCID: 5221858.

22. Eusebi LH, Rabitti S, Artesiani ML, Gelli D, Montagnani M, Zagari RM, et al. Proton pump inhibitors: Risks of long-term use. Journal of gastroenterology and hepatology. 2017 Jul;32(7):1295-302. PubMed PMID: 28092694.

23. Zhu W, Hong K. Potential Cardiovascular Risks of Proton Pump Inhibitors in the General Population. International heart journal. 2017 Apr 06;58(2):163-6. PubMed PMID: 28321021. Epub 2017/03/23. eng.

24. Gilard M, Arnaud B, Cornily JC, Le Gal G, Lacut K, Le Calvez G, et al. Influence of omeprazole on the antiplatelet action of clopidogrel associated with aspirin: the randomized, double-blind OCLA (Omeprazole CLopidogrel Aspirin) study. Journal of the American College of Cardiology. 2008 Jan 22;51(3):256-60. PubMed PMID: 18206732. Epub 2008/01/22. eng.

25. Gilard M, Arnaud B, Le Gal G, Abgrall JF, Boschat J. Influence of omeprazol on the antiplatelet action of clopidogrel associated to aspirin. Journal of thrombosis and haemostasis : JTH. 2006 Nov;4(11):2508-9. PubMed PMID: 16898956. Epub 2006/08/11. eng.

26. Shah NH, LePendu P, Bauer-Mehren A, Ghebremariam YT, Iyer SV, Marcus J, et al. Proton Pump Inhibitor Usage and the Risk of Myocardial Infarction in the General Population. PloS one. 2015;10(6):e0124653. PubMed PMID: 26061035. Pubmed Central PMCID: 4462578. 
27. Sehested TSG, Gerds TA, Fosbol EL, Hansen PW, Charlot MG, Carlson N, et al. Long-term use of proton pump inhibitors, dose-response relationship and associated risk of ischemic stroke and myocardial infarction. Journal of internal medicine. 2018 Mar;283(3):268-81. PubMed PMID: 29024109.

28. Dai C, Jiang M, Cao Q. Proton-Pump Inhibitor use and the risk of Ischaemic Stroke. Journal of internal medicine. 2018 Mar;283(3):330. PubMed PMID: 29178345.

29. Sukhovershin RA, Cooke JP. How May Proton Pump Inhibitors Impair Cardiovascular Health? American journal of cardiovascular drugs : drugs, devices, and other interventions. 2016 Jun;16(3):153-61. PubMed PMID: 26817947. Pubmed Central PMCID: 4864131.

30. Nguyen LH, Lochhead P, Joshi AD, Cao Y, Ma W, Khalili $\mathrm{H}$, et al. No Significant Association Between Proton Pump Inhibitor Use and Risk of Stroke After Adjustment for Lifestyle Factors and Indication. Gastroenterology. 2017 Dec 19. PubMed PMID: 29269313.

31. Ghebremariam YT, LePendu P, Lee JC, Erlanson DA, Slaviero A, Shah NH, et al. Unexpected effect of proton pump inhibitors: elevation of the cardiovascular risk factor asymmetric dimethylarginine. Circulation. 2013 Aug 20;128(8):845-53. PubMed PMID: 23825361. Pubmed Central PMCID: 3838201.

32. Tommasi S, Elliot DJ, Hulin JA, Lewis BC, McEvoy M, Mangoni AA. Human dimethylarginine dimethylaminohydrolase 1 inhibition by proton pump inhibitors and the cardiovascular risk marker asymmetric dimethylarginine: in vitro and in vivo significance. Scientific reports. 2017 Jun 06;7(1):2871. PubMed PMID: 28588208. Pubmed Central PMCID: PMC5460274. Epub 2017/06/08. eng.

33. Boger RH, Bode-Boger SM, Szuba A, Tsao PS, Chan JR, Tangphao O, et al. Asymmetric dimethylarginine (ADMA): a novel risk factor for endothelial dysfunction: its role in hypercholesterolemia. Circulation. 1998 Nov 3;98(18):1842-7. PubMed PMID: 9799202.

34. Wilson AM, Shin DS, Weatherby C, Harada RK, Ng MK, Nair N, et al. Asymmetric dimethylarginine correlates with measures of disease severity, major adverse cardiovascular events and all-cause mortality in patients with peripheral arterial disease. Vascular medicine. 2010 Aug;15(4):267-74. PubMed PMID: 20484311. Pubmed Central PMCID: 3131178.

35. Sehested TSG, Hlatky MA, Carlson N, Gislason GH. Reply: proton-pump inhibitor use and the risk of first-time ischemic stroke in the general population. Journal of internal medicine. 2018 Mar;283(3):331. PubMed PMID: 29105188.

36. Kaiser P, Arnold AM, Benkeser D, Zeki Al Hazzouri A, Hirsch CH, Psaty BM, et al. Comparing methods to address bias in observational data: statin use and cardiovascular events in a US cohort. International journal of epidemiology. 2018 Feb 1;47(1):246-54. PubMed PMID: 29024975.

37. Lipsitch $\mathrm{M}$, Tchetgen Tchetgen $\mathrm{E}$, Cohen T. Negative controls: a tool for detecting confounding and bias in observational studies. Epidemiology. 2010 May;21(3):383-8. PubMed PMID: 20335814. Pubmed Central PMCID: 3053408.

38. Blackburn DF, Lamb DA, McLeod MM, Eurich DT. Increased use of acid-suppressing drugs before the occurrence of ischemic events: a potential source of confounding in recent observational studies. Pharmacotherapy. 2010 Oct;30(10):985-93. PubMed PMID: 20874035.

39. Turkiewicz A, Vicente RP, Ohlsson H, Tyden P, Merlo J. Revising the link between proton-pump inhibitors and risk of acute myocardial infarction-a case-crossover analysis. European journal of clinical pharmacology. 2015 Jan;71(1):125-9. PubMed PMID: 25384436.

40. Sadr-Azodi O, Sundquist J, Ji J, Lundell L, Sundquist K. Risk of acute myocardial infarction and stroke after discharge from in-hospital care due to complicated and uncomplicated peptic ulcer disease. European journal of gastroenterology \& hepatology. 2011 Jun;23(6):461-6. PubMed PMID: 21499109.

41. Juurlink DN, Dormuth CR, Huang A, Hellings C, Paterson JM, Raymond C, et al. Proton pump inhibitors and the risk of adverse cardiac events. PloS one. 2013;8(12):e84890. PubMed PMID: 24386430. Pubmed Central PMCID: 3873988.

42. Charlot M, Grove EL, Hansen PR, Olesen JB, Ahlehoff $\mathrm{O}$, Selmer $\mathrm{C}$, et al. Proton pump inhibitor use and risk of adverse cardiovascular events in aspirin treated patients with first time myocardial infarction: nationwide propensity score matched study. BMJ.342:d2690. PubMed PMID: 21562004. Epub 2011/05/13. eng. 


\section{FIGURES}

Figure 1. Association between current use of PPIs (vs past use) and risk of hospitalization for cardiovascular or non-haemorrhagic cerebrovascular events by age, gender, or concomitant use of drugs

Stratified analysis - Current users

\begin{tabular}{|c|c|c|c|c|}
\hline Strata & & & OR $(95 \% \mathrm{Cl})$ & p-value \\
\hline \multicolumn{5}{|c|}{ Use of antithrombotics during follow-up } \\
\hline No & & $\mapsto$ & $1.52(1.44-1.61)$ & \multirow{2}{*}{0.0019} \\
\hline Yes & & $\longmapsto$ & $1.74(1.63-1.85)$ & \\
\hline \multicolumn{5}{|c|}{ Use of drugs for hypercholesterolemia } \\
\hline No & & $\mapsto-1$ & $1.58(1.50-1.66)$ & \multirow{2}{*}{0.1548} \\
\hline Yes & & $\longmapsto$ & $1.68(1.56-1.80)$ & \\
\hline \multicolumn{5}{|c|}{ Use of drugs for diabetes } \\
\hline No & & $\mapsto-1$ & $1.64(1.57-1.72)$ & \multirow{2}{*}{0.0527} \\
\hline Yes & & $\longmapsto$ & $1.46(1.32-1.63)$ & \\
\hline \multicolumn{5}{|c|}{ Use of drugs for hypertension } \\
\hline No & & $\longmapsto$ & $1.59(1.46-1.72)$ & \multirow{2}{*}{0.6961} \\
\hline Yes & & $\mapsto$ & $1.62(1.54-1.70)$ & \\
\hline \multicolumn{5}{|l|}{ Gender } \\
\hline Males & & $\mapsto$ & $1.60(1.51-1.68)$ & \multirow{2}{*}{0.5985} \\
\hline Females & & $\longmapsto$ & $1.63(1.53-1.75)$ & \\
\hline \multicolumn{5}{|l|}{ Age } \\
\hline$\leq 60$ years & & $\longmapsto$ & $1.78(1.67-1.90)$ & \multirow{2}{*}{$<0.0001$} \\
\hline \multirow[t]{2}{*}{$>60$ years } & & $\mapsto$ & $1.50(1.42-1.58)$ & \\
\hline & 0,5 & 1,5 & & \\
\hline
\end{tabular}


TABLES

Table 1. Characteristics of the case patients and of the corresponding controls included into the study

\begin{tabular}{|c|c|c|c|c|c|}
\hline & & & Cases $(\mathrm{N}=17,832)$ & Controls $(\mathrm{N}=\mathbf{8 9}, 160)$ & p-value ${ }^{a}$ \\
\hline \multicolumn{3}{|l|}{ Men, \% } & $11,575(64.91)$ & $57,875(64.91)$ & $\mathrm{MV}$ \\
\hline \multicolumn{3}{|c|}{ Age, mean (SD) } & $58.89(9.05)$ & $58.89(9.05)$ & MV \\
\hline \multicolumn{3}{|c|}{ Omeprazole } & $4098(22.98)$ & $19108(21.93)$ & \multirow{6}{*}{$<.0001$} \\
\hline \multicolumn{3}{|c|}{ Pantoprazole } & 3173 (17.79) & $16330(18.32)$ & \\
\hline \multirow{4}{*}{ PPIs, \% } & Lansopraz & & 4088 (22.93) & 20492 (22.98) & \\
\hline & \multicolumn{2}{|c|}{ Rabeprazole } & $1829(10.26)$ & $9203(10.32)$ & \\
\hline & \multicolumn{2}{|c|}{ Esomeprazole } & $4615(25.88)$ & $23932(26.84)$ & \\
\hline & \multicolumn{2}{|c|}{ Combinations $^{b}$} & $29(0.16)$ & $95(0.11)$ & \\
\hline \multicolumn{3}{|c|}{ Drugs for diabetes, $\%$} & $2978(16.70)$ & $8307(9.32)$ & $<.0001$ \\
\hline \multicolumn{3}{|c|}{ Drugs for hypertension, \% } & 12505 (70.13) & $46516(52.17)$ & $<.0001$ \\
\hline \multicolumn{3}{|c|}{ Drugs for hypercholesterolemia, \% } & $5818(32.63)$ & $19040(21.35)$ & $<.0001$ \\
\hline \multirow{3}{*}{\multicolumn{2}{|c|}{ Charlson score }} & 0 & $15431(86.54)$ & 83126 (93.23) & \\
\hline & & 1 & $1395(7.82)$ & $4197(4.71)$ & $<.0001$ \\
\hline & & $>=2$ & $1006(5.64)$ & $1837(2.06)$ & \\
\hline \multicolumn{3}{|c|}{ Antithrombotics during follow-up } & $7696(43.16)$ & $19513(21.89)$ & $<.0001$ \\
\hline \multicolumn{3}{|c|}{ Non-selective NSAIDs, \% } & $11594(65.02)$ & $57822(64.85)$ & 0,6620 \\
\hline \multicolumn{3}{|c|}{ Coxibs, $\%$} & 3914 (21.95) & $19304(21.65)$ & 0,3591 \\
\hline \multicolumn{3}{|c|}{ Corticosteroids, \% } & $4993(28.00)$ & $23630(26.50)$ & $<.0001$ \\
\hline \multirow{3}{*}{\multicolumn{2}{|c|}{ Recency of PPI use, \% }} & Current use & $4386(24.60)$ & 12828 (14.39) & \multirow{3}{*}{$<.0001$} \\
\hline & & Recent use & $781(4.38)$ & 3845 (4.31) & \\
\hline & & Past use & 12665 (71.02) & 72487 (81.30) & \\
\hline
\end{tabular}

MV: matching variables; NSAIDs: nonsteroidal anti-inflammatory drugs; PPIs: proton pump inhibitors

a According to chi-square test (PPI class, concomitant users of other drugs) or its version for the trend (categories of the Charlson comorbidity index score and of recency)

${ }^{b}$ More than one PPI at the index date 
Table 2. Association between PPI use and risk of hospitalization for cardiovascular or non-haemorrhagic cerebrovascular events

\begin{tabular}{|c|c|c|}
\hline & $\mathrm{aORs}^{\mathrm{a}}$ & $95 \% \mathrm{Cl}$ \\
\hline \multicolumn{3}{|l|}{ Exposure } \\
\hline Current vs past & 1.61 & $1.55-1.68$ \\
\hline Recent vs past & 1.15 & $1.06-1.26$ \\
\hline Past use & 1 & ref \\
\hline \multicolumn{3}{|l|}{ Starting therapy } \\
\hline Lansoprazole & 1 & ref \\
\hline Omeprazole & 0.98 & $0.93-1.03$ \\
\hline Pantoprazole & 0.97 & $0.92-1.02$ \\
\hline Rabeprazole & 0.98 & $0.92-1.05$ \\
\hline Esomeprazole & 0.98 & $0.93-1.03$ \\
\hline Combinations & 1.18 & $0.76-1.83$ \\
\hline \multicolumn{3}{|l|}{ Use of other drugs (vs No use) } \\
\hline Drugs for diabetes & 1.37 & $1.31-1.44$ \\
\hline Drugs for hypertension & 1.77 & $1.70-1.84$ \\
\hline Drugs for hypercholesterolemia & 1.34 & $1.29-1.40$ \\
\hline Antithrombotics during follow-up & 2.37 & $2.29-2.46$ \\
\hline Non-selective NSAIDs & 0.94 & $0.91-0.98$ \\
\hline Coxibs & 0.94 & $0.90-0.98$ \\
\hline Corticosteroids & 1.03 & $0.99-1.07$ \\
\hline
\end{tabular}

\begin{tabular}{cll}
\hline Charlson comorbidity index & & \\
\hline 0 & 1 & ref \\
1 & 1.37 & $1.28-1.47$ \\
$\geq 2$ & 1.83 & $1.68-1.99$ \\
\hline
\end{tabular}

\footnotetext{
a Model adjusted for type of PPI, antidiabetic drug use, antihypertensive drug use, lipidlowering drug use, NSAID use (except coxibs), coxib use, corticosteroid use, and Charlson comorbidity index.
} 
Table 3. Association between PPI use and risk of hospitalization for cardiovascular and non-haemorrhagic cerebrovascular events

\begin{tabular}{llll}
\hline & & aORs & 95\%Cl \\
\hline $\begin{array}{l}\text { Cardiovascular } \\
\text { events }\end{array}$ & Current vs Past & 1.71 & $1.63-1.81$ \\
\hline $\begin{array}{l}\text { Recent vs Past } \\
\text { events }\end{array}$ & 1.13 & $1.02-1.27$ \\
\hline
\end{tabular}

a Model adjusted for type of PPI, antidiabetic drug use, antihypertensive drug use, lipidlowering drug use, NSAID use (except coxibs), coxib use, corticosteroid use, and Charlson comorbidity index.

Table 4. Risk of hospitalization for cardiovascular or non-haemorrhagic cerebrovascular events by recency of $\mathrm{H} 2$ antagonist use

\begin{tabular}{llll}
\hline & & aORs $^{\mathrm{a}}$ & $95 \% \mathrm{Cl}$ \\
\hline Recency of H2 antagonist & Current vs past & 0.89 & $0.51-1.54$ \\
use & Recent vs past & 1.04 & $0.39-2.78$
\end{tabular}

a Model adjusted for type of $\mathrm{H} 2$ antagonist, antidiabetic drug use, antihypertensive drug use, lipid-lowering drug use, NSAID use (except coxibs), coxib use, corticosteroid use, and Charlson comorbidity index. 


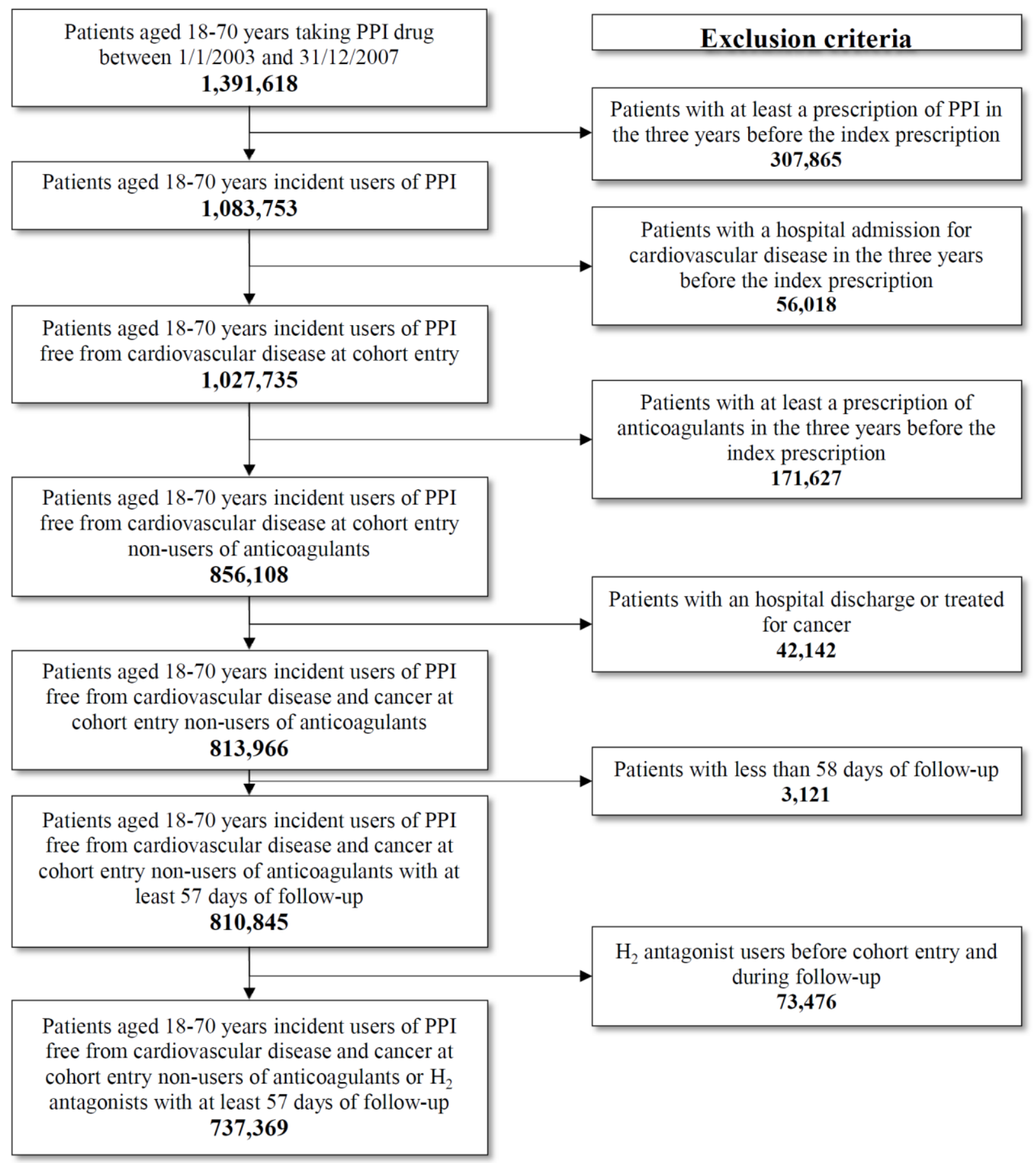


Supplemental Table 1. Sensitivity analysis: risk of hospitalization for cardiovascular and for non-haemorrhagic cerebrovascular events by different definition of recency of PPI use

\begin{tabular}{llll}
\hline & & ORs & $95 \% \mathrm{Cl}$ \\
\hline \multirow{2}{*}{ Recency (B) } & Current vs past & 1.67 & $1.60-1.75$ \\
& Recent vs past & 1.23 & $1.11-1.36$ \\
\hline \multirow{2}{*}{ Recency (C) } & Current vs past & 1.71 & $1.63-1.79$ \\
& Recent vs past & 1.31 & $1.231-41$ \\
\hline
\end{tabular}

Recency (B) with other windows of exposure: current $<=14$ days, recent $15-28$ days, past $>28$ days.

Recency (C) estimated as time between last prescription and event date and current $<=28$ days, recent $28-56$ days, past $>56$ days 